\title{
Stable Carbon and Nitrogen Isotope Variability of Bone Collagen to Determine the Number of Isotopically Distinct Specimens
}

\author{
Corrie Hyland ${ }^{1,2}$ (D) Michael B. Scott ${ }^{1,2}$ (D) Jennifer Routledge ${ }^{1}$ (D) $\cdot$ Paul Szpak $^{1}$ (D)
}

Accepted: 11 August 2021 /Published online: 1 September 2021

(c) The Author(s) 2021, corrected publication 2021

\begin{abstract}
Archaeological and palaeontological excavations frequently produce large quantities of highly fragmentary bone. These bones can help to answer questions regarding past environments and human and animal lifeways via a number of analytical techniques but this potential is limited by the inability to distinguish individual animals and generate sufficiently large samples. Using stable carbon and nitrogen isotope values of bone collagen $\left(\delta^{13} \mathrm{C}, \delta^{15} \mathrm{~N}\right)$, we present a metric to identify the number of isotopically distinct specimens (NIDS) from highly fragmented faunal assemblages. We quantified the amount of intra-individual isotopic variation by generating isotopic data from multiple elements from individual animals representing a wide variety of taxa as well as multiple samples from the same skeletal element. The mean intra-individual variation (inter-bone) was $0.52 \%$ o $(\sigma=0.45)$ (Euclidean distance between two points in isotopic bivariate space), while the mean intra-bone variation was $0.63 \%$ o $(\sigma=0.06)$. Using archaeological data consisting of large numbers of individual taxa from single sites, the mean inter-individual isotopic variation was $1.45 \%$ o $(\sigma=1.15)$. We suggest the use of $1.50 \%$ in bivariate $\left(\delta^{13} \mathrm{C}, \delta^{15} \mathrm{~N}\right)$ space as a metric to distinguish NIDS. Blind tests of modelled archaeological datasets of different size and isotopic variability resulted in a rate of misclassification (two or more elements from the same individual being classified as coming from different individuals) of $<5 \%$.
\end{abstract}

Keywords Zooarchaeology · Isotopic variability · Bone turnover · Identifying distinct individuals $\cdot$ NISP

Corrie Hyland

corrie.hyland@hertford.ox.ac.uk

$\triangle$ Paul Szpak

paulszpak@trentu.ca

1 Department of Anthropology, Trent University, Peterborough, ON K9L 0G2, Canada

2 School of Archaeology, University of Oxford, Oxford OX1 3TG, UK 


\section{Introduction}

Highly fragmented faunal remains at archaeological sites present challenges when attempting to determine the minimum number of individuals (MNI) within past animal populations. This is particularly noteworthy in the context of analyses involving these remains such as radiocarbon dating, ancient DNA, and stable isotope analysis that require the sampling of discrete individuals. In select cases, wherein fragmentary remains have been sampled for stable isotope analysis and AMS radiocarbon dating, researchers have identified samples to a taxon through inferences based on their stable carbon $\left(\delta^{13} \mathrm{C}\right)$ and nitrogen $\left(\delta^{15} \mathrm{~N}\right)$ isotope compositions (Corbett et al., 2008; Gorlova et al., 2015; Szpak et al., 2019). In these contexts, the MNI is almost certainly a significant underestimation of the true number of distinct individuals and the MNI may be 1 even with a large number of individual specimens (NISP). Individual animals may have variable diets, meaning it may be possible to differentiate individuals within the same species based on stable isotopic compositions. In order to do so, however, it is necessary to understand the amount of variation in $\delta^{13} \mathrm{C}$ and $\delta^{15} \mathrm{~N}$ that exists within individuals and how this variation compares to that which exists among individuals.

Schoeninger et al. (1983) examined intra-individual variation and inter-individual isotopic variation for multiple bones from rabbits and minks fed controlled diets. Differences in the isotopic composition of bone collagen within an individual were approximately the same as between individuals within a population with a shared diet. The level of intra-individual variability observed in that study (approximately $1.0 \%$ or less for $\delta^{13} \mathrm{C}$ and $\delta^{15} \mathrm{~N}$ ) was echoed by later comparisons of $\delta^{13} \mathrm{C}$ values in wild deer and vole populations (Hobson \& Schwarcz, 1986) and $\delta^{13} \mathrm{C}$ and $\delta^{15} \mathrm{~N}$ values among bones of modern marine mammals (Clark et al., 2017). Intra-individual differences for these marine mammals with variable diets were attributed to the varying rates at which different bones remodel, particularly distal limb elements relative to long bones.

For animals with diets that vary over time, intra-individual isotopic variation should be driven by varying turnover rates. This assumption is informed by the recorded differences in turnover rates among bones (Snyder et al., 1975) as well as between cortical and trabecular bone tissues (Manolagas, 2000). Specific to human bone collagen, turnover rates are relatively rapid in young individuals and decrease with age to $<5 \%$ per annum in adults (Geyh, 2001; Hedges et al., 2007; Stenhouse \& Baxter, 1979). Studies with other species have found bone collagen turnover to be slower than in other tissues (Hobson \& Clark, 1992), and that adult animal bones likely still contain collagen formed during adolescence (Matsubayashi \& Tayasu, 2019). A previous study comparing cortical and trabecular bone collagen turnover within two humans born prior to, and deceased after the start of atomic weapons testing, found that differences in $\Delta^{14} \mathrm{C}$ between tissue types indicated trabecular bone collagen turns over at a slightly faster (albeit undefined) rate, although turnover of both tissues may slow down immensely later in life (Ubelaker et al., 2006). Beyond that study, systematic research on potential differences in bone collagen turnover between bone tissue types has been scarce. 
Several studies have attempted to identify human dietary shifts by sampling multiple bones from the same individual or multiple sections of the same bone. Intraindividual differences in the isotopic composition of bone collagen, interpreted as shifts in diet based on $\delta^{13} \mathrm{C}$ and $\delta^{15} \mathrm{~N}$ values, have on occasion exceeded $1.6 \%$ (Cheung et al., 2017; Cox \& Sealy, 1997; Fahy et al., 2017; Pollard et al., 2012; Sealy et al., 1995). Differences of this magnitude only occurred within a few individuals in each study. In most other cases, intra-individual differences in either $\delta^{13} \mathrm{C}$ and $\delta^{15} \mathrm{~N}$ fall below 1.6\%o (Clark et al., 2017), often approximating reported uncertainties of isotopic measurements (Jørkov et al., 2009; Gillis et al., 2013; RiofríoLazo \& Aurioles-Gamboa, 2013; Olsen et al., 2014; Webb et al., 2016). Studies aimed at examining both intra-individual and inter-individual variation have been restricted in terms of sample sizes (i.e. only sampling a few bones or a small number of individuals), necessitating more robust investigation. Moreover, as we demonstrate, methodological concerns related to lipid extraction may inflate the extent of intra-individual variation in modern specimens.

The goal of our study was to characterise the intra-individual variation of $\delta^{13} \mathrm{C}$ and $\delta^{15} \mathrm{~N}$ in bone collagen of various modern marine, freshwater, and terrestrial fauna and compare that variation with the inter-individual variation of populations of archaeological fauna. We measured the Euclidean distance between $\delta^{13} \mathrm{C}$ and $\delta^{15} \mathrm{~N}$ values from skeletal elements, within and between individuals, to develop a probabilistic metric that two bone fragments represent distinct individuals.

\section{Materials and Methods}

\section{Intra-individual Analyses}

Carcasses and partially processed bones of identifiable individual animals were collected for stable isotope analysis. Animals were sought that would represent a wide range of habitat types (marine, freshwater, terrestrial) and levels of expected variation in diets (migratory wild animals, wild animals with limited ranges, and agricultural animals) (Online Resource 2). Specifics of individual diets were not known; however, reasonable assumptions can be made based on husbandry practices and species ecology. These animals included complete carcasses donated by local farms, bones from household cooking, bones prepared for other research projects, and articulated bones sold as dog chews (Table 1). The bones were cleaned of any remaining flesh, cartilage, or tendon by manual abrasion, simmering in water, or through steaming. After defleshing, a NSK dental drill was used to cut $100 \mathrm{mg}$ of bone for collagen extraction.

\section{Intra-bone Analyses}

To determine the amount of expected isotopic variation within a single bone, thirteen harp seal humeri were selected for additional intra-bone comparisons. Harp seals are a species with an isotopically diverse range of food sources due to their 
Table 1 A list of the species analysed for intra-individual isotopic variability, place of origin, number of individuals, and the number of samples taken from those individuals (samples excluded due to potential lipid contamination are not included)

\begin{tabular}{lllll}
\hline Species & Common name & Origin of samples & $n$ Ind & $n$ samples
\end{tabular}

\section{Freshwater fish}

Esox americanus

Perca flavescens

Pickerel (wild)

Yellow perch (wild)

Lake Ontario, Canada $\quad 1 \quad 4$

$\begin{array}{lll}\text { Lake Ontario, Canada } & 1 & 4 \\ 1 & 5\end{array}$

\section{Marine fish}

Sebastes alutus

Pacific ocean perch (wild) Coastal British Columbia, 115

Sebastes babcocki

Redbanded rockfish (wild) Coastal British Columbia, $\quad 1 \quad 2$

Canada

Marine mammal

Pagophilus groenlandicus

Harp seal (wild)

$\begin{array}{lll}\text { Newfoundland, Canada } & 1 & 1 \\ & 1 & 3 \\ 2 & 4 \\ 2 & 5 \\ 1 & 6 \\ 6 & 7\end{array}$

\section{Terrestrial avian}

\section{Meleagris gallopavo domestica}

Colaptes auratus

Leuconotopicus villosus

\section{Terrestrial mammal}

Bos taurus

Bos taurus

Sus scrofa domesticus

Mustela frenata

Procyon lotor
Turkey

Northern flicker (wild)

Domestic cattle

Domestic cattle

Pig

Long-tailed weasel (wild)

Raccoon (wild)

Hairy woodpecker (wild)

\section{Household food by- products}

Horse ranch,

Peterborough,

Ontario, Canada

Horse ranch,

Peterborough,

Ontario, Canada

$\begin{array}{lll}\text { Articulated bones of dog } & 1 & 5 \\ \text { chew } & 3 & 6 \\ & 2 & 7\end{array}$

Dairy farm, Windsor, $\quad 1 \quad 9$

Ontario, Canada

Household food by- $\quad 1 \quad 9$

products

Peterborough, Ontario, Canada

Dairy farm, Windsor, Ontario, Canada 
migratory behaviour (Falk-Petersen et al., 2004). If isotopic differences within a single bone are to be expected as a result of growth or muscle use impacting bone turnover, it was believed that a migratory species would be a strong candidate to make such observations. The size of the skeletal elements and lack of epiphyseal fusion suggested that the seal humeri were undergoing growth up to the time of death. Three samples were taken from each of the humeri at the diaphysis, the epiphyseal condyles, and deltoid tuberosity.

\section{Collagen Extraction and Purification}

All samples were subjected to a lipid extraction procedure which consisted of sonication in a 2:1 chloroform: methanol (v/v) solution for $20 \mathrm{~min}$ with repeated rinses until the resulting solution was clear (up to a maximum of three rinses) (Folch et al., 1957). Samples were demineralised in $0.5 \mathrm{M} \mathrm{HCl}$, until soft, then placed in a $0.1 \mathrm{M}$ $\mathrm{NaOH}$ solution for $30 \mathrm{~min}$ to remove any additional lipids or possible humic contaminants (repeated up to 3 times). Finally, samples were refluxed in $0.01 \mathrm{M} \mathrm{HCl}$ at $75^{\circ} \mathrm{C}$ for $48 \mathrm{~h}$ and lyophilised.

Samples that exhibited signs of lipid contamination (as described below) were subjected to an additional lipid extraction procedure based upon the method detailed by Bligh and Dyer (1959). Lyophilised collagen was redissolved in type I water and subsequently mixed with chloroform:methanol in proportions of 2:1:0.8 (chloroform:methanol:water). The solvent-collagen mixture was sonicated for $1 \mathrm{~h}$ at approximately room temperature before tubes were placed in a centrifuge $(2500 \mathrm{rpm} \times 20 \mathrm{~min})$. A clear top layer containing a methanol-water-collagen mixture was transferred to a separate tube and a 1:0.8 mixture of methanol:water was added to the remaining chloroform-lipid layer in the original tube. The process was repeated for additional collagen recovery. Methanol-water-collagen samples were placed in a dry bath $\left(62{ }^{\circ} \mathrm{C}\right)$ for at least $24 \mathrm{~h}$ to evaporate excess methanol. The remaining water-collagen mixture was again placed in a 2:1:0.8 chloroform:methanol:water solution and collagen was extracted using the same above method to remove any remaining lipids. Upon the evaporation of any remaining methanol as described above, collagen samples were once again lyophilised.

\section{Stable Isotope Analysis}

All samples were analysed using a EuroEA 3000 Elemental Analyzer (EuroVector $\mathrm{SpA}$ ) coupled to a $\mathrm{Nu}$ Horizon (Nu Instruments) continuous flow isotope ratio mass spectrometer (CF-IRMS) at the Trent University Water Quality Center. Ten percent of the samples were analysed in duplicate to assess sample homogeneity. Calibration to international reference scales of VPDB and AIR was completed using a two-point calibration curve based on USGS40 $\left(\delta^{13} \mathrm{C}-26.39 \pm 0.04 \% o, \delta^{15} \mathrm{~N}-4.52 \pm 0.04 \% o\right)$ and USGS41a $\left(\delta^{13} \mathrm{C}+36.55 \pm 0.08 \% o, \delta^{15} \mathrm{~N}+47.55 \pm 0.15 \% \circ\right)$. The quality assurance standards used within each run to determine accuracy were in house standards of caribou bone collagen (SRM-1: $\delta^{13} \mathrm{C}-19.36 \pm 0.11 \%$ o, $\delta^{15} \mathrm{~N}+1.81 \pm 0.10 \%$ ), walrus bone collagen (SRM-2: $\delta^{13} \mathrm{C}-14.82 \pm 0.06 \%$ o, $\delta^{15} \mathrm{~N}+15.59 \pm 0.11 \%$ ), and 
polar bear bone collagen (SRM-14: $\delta^{13} \mathrm{C}-13.66 \pm 0.07 \%$ o, $\delta^{15} \mathrm{~N}+21.62 \pm 0.12 \%$ ). The total analytical uncertainty was $\pm 0.15 \%$ for $\delta^{13} \mathrm{C}$ and $\pm 0.36 \%$ for $\delta^{15} \mathrm{~N}$.

Collagen yields were calculated for all samples and were used to assess the quality of collagen along with wt\% $\mathrm{C}$, wt\% $\mathrm{N}$, and atomic $\mathrm{C}: \mathrm{N}$ ratio (S1) (Ambrose, 1990; DeNiro, 1985). The presence of lipids within the collagen was assessed by identifying correlations between the $\delta^{13} \mathrm{C}$ and $\mathrm{C}: \mathrm{N}$ ratios within the samples of each individual (Guiry \& Szpak, 2020) (Figure S1). Values that displayed a correlation were excluded from the analysis because the $\delta^{13} \mathrm{C}$ values likely represent lipid contamination and variable amounts of lipid contamination among bones within an individual will serve to artificially increase the amount of isotopic variation within an individual.

\section{Inter-individual Analyses}

Archaeological stable isotope data from previously published and unpublished studies were used to determine the amount of isotopic variation which could be expected among individuals of the same species from the same geographic region. To be included, the data had to meet three criteria: clear information on analytical uncertainty was available, the isotopic compositions represented distinct individuals, and the samples had to be identified to the genus or species level. Sample datasets that represented marine and terrestrial fauna from wild and agricultural contexts were used to illustrate a wide range of potential inter-individual isotopic variability (Table 2).

\section{Data Analysis}

The isotopic variation for all groups examined was determined by calculating the Euclidean distance between two points $\left(\delta^{13} \mathrm{C}, \delta^{15} \mathrm{~N}\right)$ in bivariate space (Fig. 1). For intra-individual analysis, every bone from one individual was compared to all of the other bones from that individual. For intra-bone analysis, the sampling sites within a single bone were compared to one another. For the inter-individual analysis, the $\delta^{13} \mathrm{C}$ and $\delta^{15} \mathrm{~N}$ values of each individual were compared to all other individuals of the same archaeological context (strata, feature, or site). These comparisons were created using distance matrices calculated through R (version 3.5.3) (R Core Team, 2013). Animals were grouped into categories according to expected levels of isotopic variation. The distribution of distance values between these categories and habitat types (marine, freshwater, terrestrial) were compared for the intra-individual data sets (Online Resource 1-Discussion).

To identify if significant differences existed between intra-individual, interindividual, and intra-bone isotopic variability, parametric statistical tests were performed. Due to large sample sizes $(>50)$, a normal distribution of the distance data was assumed under the central limit theorem (Elliott \& Woodward, 2007:26). A one-way analysis of variance (ANOVA) was performed to determine if there were significant differences between the mean distance values of the intra-individual, intra-bone, and inter-individual isotopic distance values. 


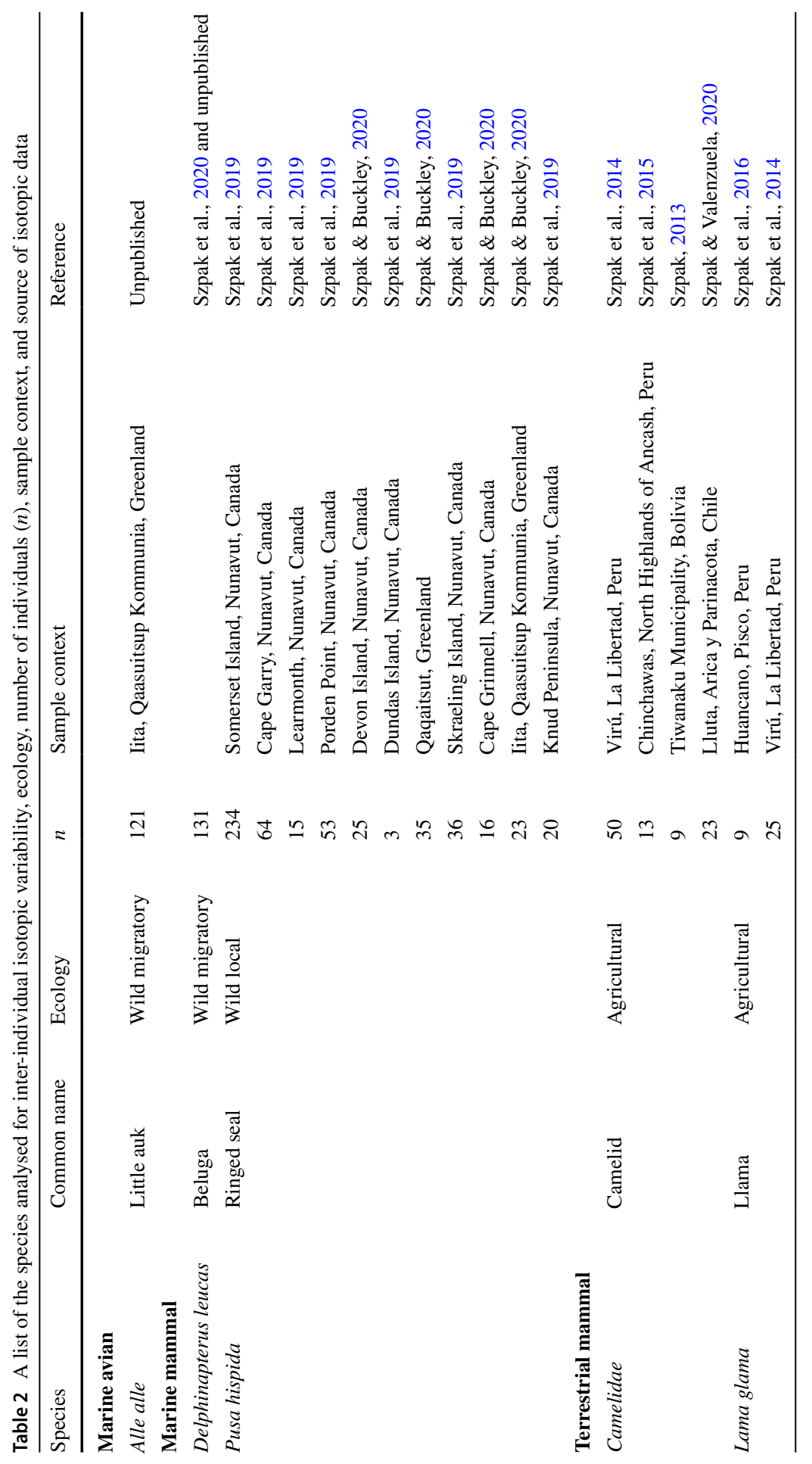


Fig. 1 Representation of the calculations made for intrabone (blue) and intra-individual (gold) isotopic variation by calculating the distances between the $\delta^{13} \mathrm{C}$ and $\delta^{15} \mathrm{~N}$ values within a bone and between different bones of an individual in twodimensional isotopic space

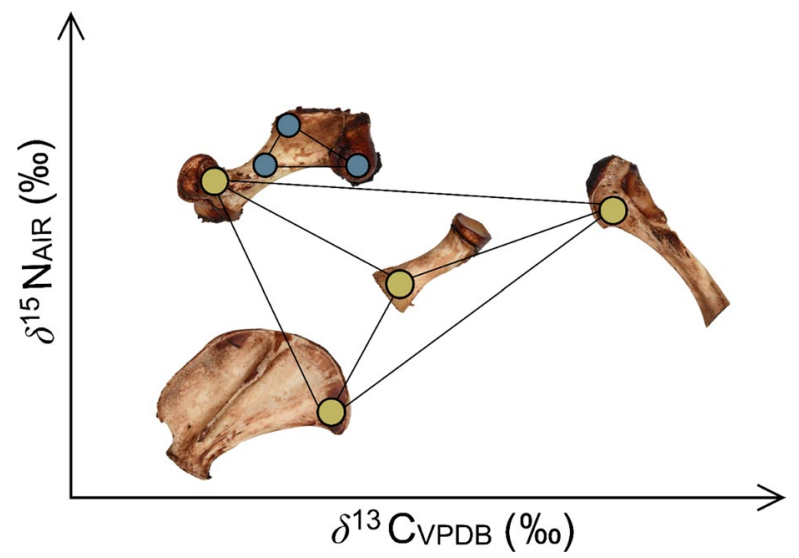

\section{Testing the Ability to Identify Distinct Individuals}

An additional 263 bone collagen samples were collected to determine the utility of using the determined metric for the expected intra-individual distance in isotopic space as a tool to identify the number of isotopically distinct specimens (NIDS), hereafter referred to as the "NIDS metric" (Table 3). These samples were processed for stable carbon and nitrogen isotope analysis and assessed for lipid contamination using the methods outlined previously. Of these 263 additional samples, 206 samples provide no indication of lipid contamination (Online Resource 3 and 4). These additional samples represented 20 new individuals and one resampled individual. We generated these additional data to test the NIDS metric to avoid circular reasoning — if the same intra-individual isotopic dataset that informed the metric was used to test it, the metric would naturally be extremely effective. A previously sampled raccoon was resampled to include at least one individual displaying an extreme level of intra-individual variation and thereby increasing the odds that the metric would make errors of misclassification.

The isotopic compositions of the additional samples were randomly ordered and ten sub-samples were selected. These 10 sub-samples were assessed for their distance in isotopic space by unweighted pair group method with arithmetic mean (UPGMA) hierarchical clustering based on Euclidean distance in PAST. The number of distinct clusters at the NIDS metric was recorded in comparison to the true number of distinct individuals represented in the 10 bone collagen samples. The data that we generated for testing our NIDS metric contained a much higher MNI:NISP ratio than would be expected in a real archaeological assemblage. To more closely approximate real-world conditions, we simulated isotopic data for additional individuals using distributions for intra- and inter-individual variation informed by our real data (Online Resource 2). We then repeated our UPGMA classification with these modelled data being added to the real data $(n=5,15,25,35$, and 45). Five thousand iterations of a random sampling of 10 bone collagen samples were conducted for each of the different population sizes (Online Resource 2). 


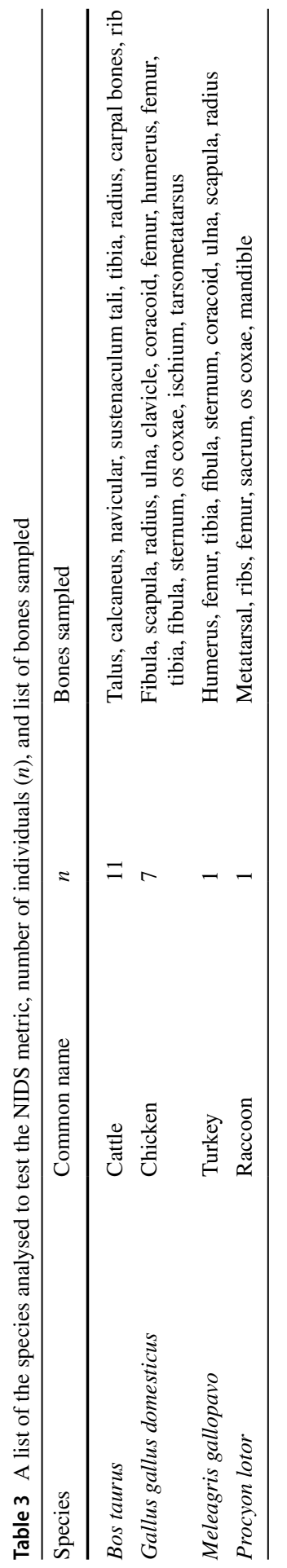


Our estimation of the probability of misclassifying multiple elements from the same individual as being from distinct individuals was informed by the approach taken by an analyst using this metric to select samples in a manner similar to using a morphological MNI. Figure 2 illustrates three examples in which there are ten specimens and seven distinct individuals. If the analyst used the NIDS metric to select distinct individuals, it is possible, but not certain in each instance that they could sample the same individual twice. In Fig. 2A, the probability of misclassification is 0.14 since they would select three specimens: the first would be from individual 1, the second would be from individual 3, while the third would have a $1 / 7$ chance of being from individual 1 . The probability of misclassification in Fig. 2B is 0.125 . The analyst would select four specimens and using the NIDS metric, individual 1 is the only one that could be misclassified. There is a $1 / 2$ and $1 / 4$ chance of selecting an element from individual 1 and overall a $1 / 8$ chance that they would select two elements from individual 1 . Figure $2 \mathrm{C}$ is more complicated since either (or both) individual 1 and 2 could be misclassified. The probability of selecting two elements from either individual 1 or 2 is 0.375 or $(1 / 2) *(1 / 2)+(2 / 3) *(1 / 2)$. The probability of sampling two elements from both individual 1 and individual 2 is 0.042 or $(1 / 2) *(1 / 2) *(2 / 3) *(1 / 2)$. The number of misclassifications was recorded for each random sampling based on the number of times two or more bones of the same individual were identified as isotopically distinct specimens based on the NIDS metric of $1.5 \%$ (Online Resource 2).
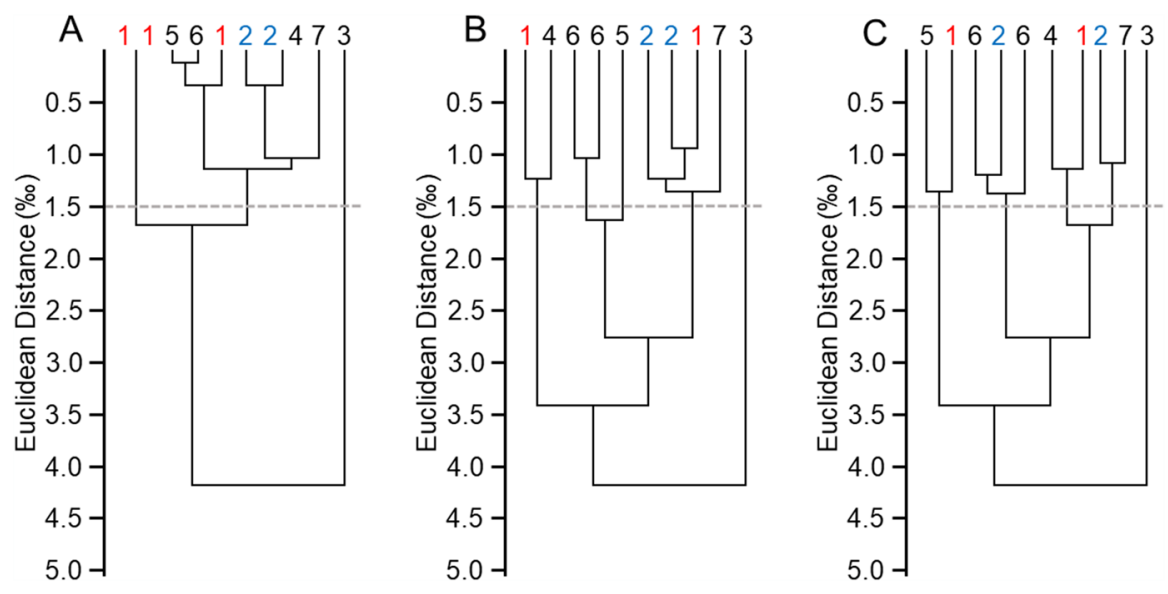

Fig. 2 Three examples to illustrate how an analyst would use the NIDS metric $(1.50 \%$ ) to determine the number of isotopically distinct samples and how the probability to misclassify samples was calculated. Coloured numbers highlight when multiple bones are from the same individual (example in panel A: 3 bones belong to Individual 1 (red) and 2 bones belong to Individual 2 (blue)). The probability to misclassify samples increases from panels A to C (A 0.14 ; B $0.125 ; \mathbf{C ~} 0.375$ to misclassify individual 1 or 2 and 0.042 to misclassify individual 1 and 2) 


\section{Results}

\section{Quantifying Variation}

Of the 422 bone collagen samples prepared for analysis to characterise intra-individual isotopic variation, 224 had $\mathrm{C}: \mathrm{N}_{\text {atomic }}$ outside the acceptable range or showed correlations between $\delta^{13} \mathrm{C}$ values and C: $\mathrm{N}_{\text {atomic }}$ within individuals (Online Resource 3 ). Fish represented most of the samples that were removed from analysis due to lipid contamination or excessive collagen loss during demineralisation. The remaining dataset included 198 bone collagen samples, which were used to calculate the isotopic distance between bones of the same individual (Online Resource 4 ).

The distribution of the isotopic distance calculations revealed differences between the mean isotopic distance values of intra-bone, intra-individual, and inter-individual comparisons (Fig. 3). A one-way ANOVA test comparing the isotopic distance calculations of the intra-bone, intra-individual, and inter-individual comparisons showed a statistically significant difference between the mean values of these groups $\left(F_{(2)}=164.5, p<0.001\right)$. The mean isotopic distance value of the inter-individual data was the highest at $1.45 \%$ with a 5 th to 95 th percentile range of 0.09 to $1.45 \%$ o (Table 4). The mean isotopic distance value for the intra-individual comparisons was the lowest at $0.52 \%$ with a 5 th to 95 th percentile range of 0.03 to $1.25 \%$ (Table 4 ). The proposed NIDS metric of $1.50 \%$ is therefore above the 95th percentile for the intra-individual comparisons of this study. While the mean intra-bone isotopic distance $(0.63 \%$ ) was larger than the mean intra-individual isotopic distance $(0.52 \%)$, the intra-bone comparisons had the smallest range $(1.22 \%$ ) compared to either the intra-individual $(2.79 \%$ ) or the inter-individual (11.04\%o) comparisons (Table 4). Results and additional discussion of the isotopic distance calculations for animals from different ecological backgrounds are provided in the Online Resources (Online Resource 1).

\section{NIDS Metric Testing}

Of the 263 additional samples prepared for stable isotope analysis, 57 were excluded from further analysis due to $\mathrm{C}: \mathrm{N}_{\text {atomic }}$ values outside of the acceptable range or correlations between $\delta^{13} \mathrm{C}$ values and C: $\mathrm{N}_{\text {atomic }}$ values within individual samples (Online Resource 3). Most of the excluded samples were from chickens. The remaining 206 bone collagen samples were used to test the efficacy of the NIDS metric (Online Resource 5).

The NIDS metric tended to underestimate the true number of distinct individuals. In our simulations, the number of distinct individuals was twice the average NIDS. The summed probability of misclassifying the same individual as two or more distinct individuals was between 2.75 and $7.49 \%$ with the lowest summed probability of error occurring in the datasets with the highest true number of distinct individuals and total specimens (Table 5). We did not assess the efficacy of the NIDS metric in terms of underestimating the true number of individuals. 


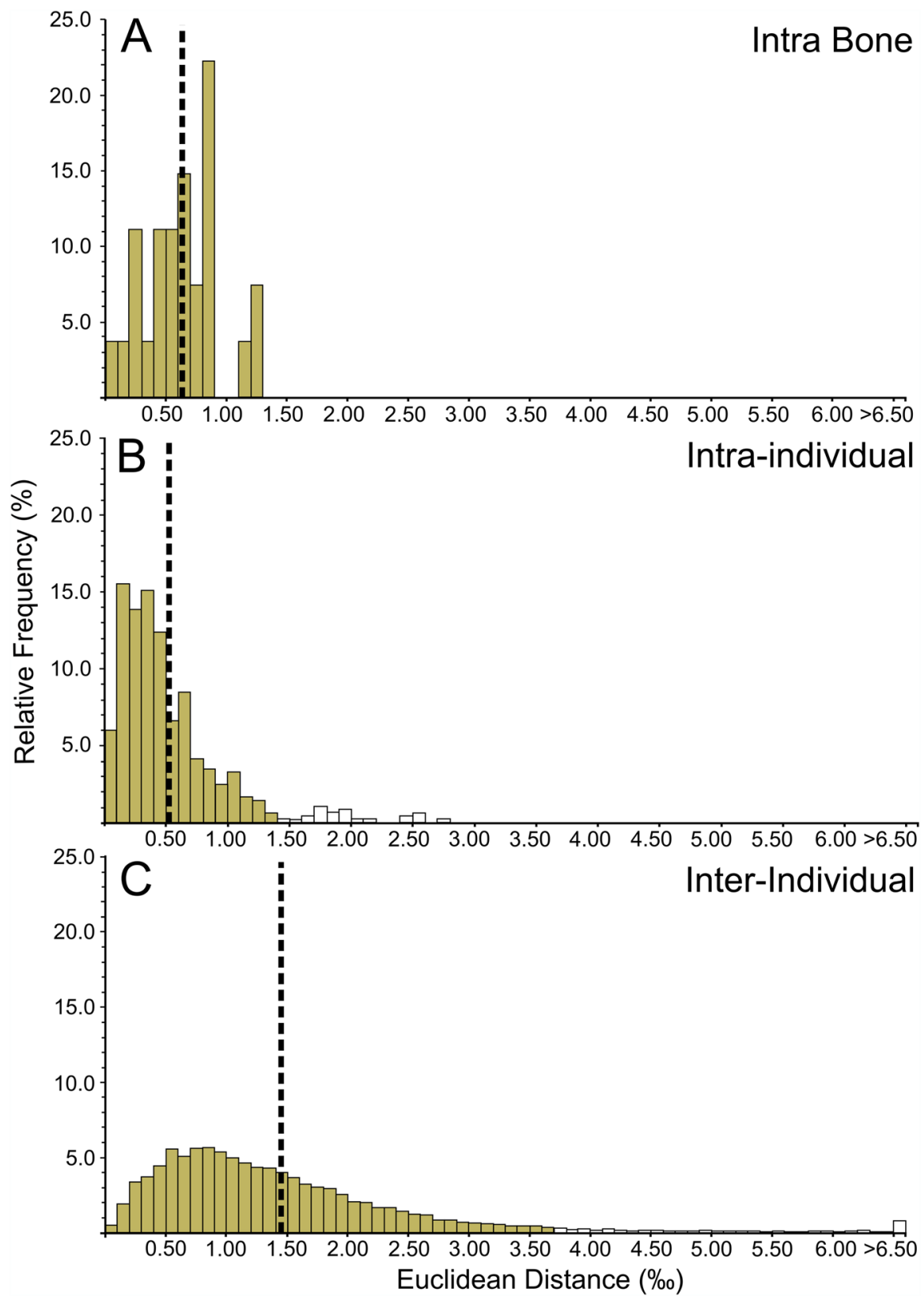

Fig. 3 Histograms showing the distribution of the distances in isotopic space between $\delta^{13} \mathrm{C}$ and $\delta^{15} \mathrm{~N}$ values obtained from multiple samples within a single bone (A), multiple bones sampled within one individual (B), and multiple individuals within one species (C). Dashed lines represent the mean value for each dataset and unfilled bars represent values outside two standard deviations from the mean value 
Table 4 Summary statistics for the calculated distances between $\delta^{13} \mathrm{C}$ and $\delta^{15} \mathrm{~N}$ values in isotopic space $(\% \circ)$

\begin{tabular}{llllllll}
\hline Sample group & $n$ & Mean & $\sigma$ & Min & Max & 5th percentile & 95th percentile \\
\hline Inter-individual & 15,802 & 1.45 & 1.15 & 0.00 & 11.04 & 0.28 & 3.49 \\
Intra-individual & 484 & 0.52 & 0.45 & 0.01 & 2.80 & 0.09 & 1.45 \\
Intra-bone & 27 & 0.63 & 0.06 & 0.03 & 1.25 & 0.03 & 1.25 \\
\hline
\end{tabular}

Table 5 Results of testing the $1.50 \%$ metric for the number of isotopically distinct specimens (NIDS) with an increased number of true distinct individuals in the randomly selected 10 bone sampling datasets and $10^{3}$ iterations

\begin{tabular}{lll}
\hline $\begin{array}{l}\text { True number of dis- } \\
\text { tinct individuals }\end{array}$ & $\begin{array}{l}\text { Number of misclas- } \\
\text { sifications }\end{array}$ & $\begin{array}{l}\text { Summed probability } \\
\text { of misclassification }\end{array}$ \\
\hline 36 & 150 & $6.2 \%$ \\
46 & 149 & $7.5 \%$ \\
56 & 99 & $3.5 \%$ \\
66 & 68 & $2.8 \%$ \\
\hline
\end{tabular}

\section{Discussion}

\section{Distinguishing Values for Inter- vs. Intra-individual Variation}

The average isotopic distance value for inter-individual comparisons was $1.45 \%$ o while the intra-individual average was only $0.52 \%$ (Table 4). Inter-individual isotopic distance calculations were also found to have a larger standard deviation (mean: $1.15 \%$ ) as well as an absolute range of values (11.04\%o) when compared to the intra-individual isotopic distance calculation (mean: $0.52 \%$, range: $2.79 \%$ ). While not a novel finding, these results support the hypothesis that bone collagen $\delta^{13} \mathrm{C}$ and $\delta^{15} \mathrm{~N}$ values could be useful for identifying distinct individuals.

To distinguish what level of isotopic variation represents values beyond those expected from intra-individual comparisons, we recommend using the upper limit of the $2 \sigma$ range of the mean intra-individual isotopic distance calculations, $1.50 \%$ as the NIDS metric. Isotopic distance values below $1.50 \%$ represent over $95 \%$ of the calculated range in intra-individual isotopic comparisons in our data, which is the most comprehensive examination of intra-individual isotopic variation published to date (Table 4). Using a difference of $1.50 \%$ in isotopic space to distinguish bones from different individuals will almost certainly result in an underestimate of the true number of individuals. Along similar lines, MNI indices, which are frequently used for selecting samples for isotopic, radiocarbon, or ancient DNA analyses, likewise provide an underrepresentation of the true number of individuals, especially in highly fragmentary assemblages (Marshall \& Pilgram 1993).

Our average value calculated for intra-individual variability $(0.52 \%)$ is low considering that values first observed by Schoeninger et al. (1983) for individuals fed monotonous diets suggest an individual variation of $1.0 \%$ or less in either $\delta^{13} \mathrm{C}$ or $\delta^{15} \mathrm{~N}$. These data suggest that to clearly distinguish different individuals with this 
method the population must have high isotopic variability. It is important to bear in mind, however, that we observed much greater variation, particularly for $\delta^{13} \mathrm{C}$ in individuals where variable lipid contamination was detected (Online Resource 3). Based on our data, we suspect that the amount of intra-individual variation observed by Schoeninger et al. (1983) was artificially inflated by variable contamination with lipids in some of the bones, especially considering the monotonous diet of the animals involved in their study.

\section{NIDS}

The NIDS metric will most likely distinguish individuals more often in populations in which local food sources are isotopically variable, individuals consume different proportions of food sources, or individuals experience major shifts in their diet, although such instances could raise the potential for misclassification. Conversely, if it is applied to a population in which diet is similar among most individuals (e.g. a terrestrial herbivore in an environment devoid of $\mathrm{C}_{3}$ plants), the potential for misclassification should be low. The $1.50 \%$ NIDS metric we have proposed is aimed at being more conservative and avoiding misclassification while being nonetheless suitable for use with archaeological remains, wherein diet is largely unknown. A survey of past archaeological isotope literature by Clark et al. (2017) found most intra-individual ranges $\leq 1.2 \%$ or both $\delta^{13} \mathrm{C}$ and $\delta^{15} \mathrm{~N}$, fitting within our proposed $1.50 \%$ isotopic distance range.

While many distinct individuals may not be classified as distinct using the $1.50 \%$ o isotopic distance range for calculating NIDS (creating a potentially high amount of type II errors), this technique has a low potential for misclassifying multiple bones of the same individual as distinct individuals (low amount of type I errors). While we have suggested this is desirable when using this method to identify distinct individuals for techniques such as stable isotope analysis, radiocarbon dating, ZooMS, and aDNA, the NIDS metric is probabilistic and researchers can elect to use a different value depending on the goals of their project. For example, a value of $2.0 \%$ for the NIDS isotopic distance range would be even less likely to result in the sampling of the same individual twice, whereas a value of $1.0 \%$ could increase sample size, with the caveat that a greater potential for resampling may occur.

\section{Intra-individual Isotopic Variation and the Role of Collagen Turnover}

Within our dataset, the average intra-bone isotopic distance measurement $(0.63 \%$ ) is significantly greater than for intra-individual comparisons, yet still below the $1.50 \%$ metric for distinguishing individuals (Table 4). A value below $1.50 \%$ could then result in misclassification of either the same bones of an individual or the same fragments of a single bone, although values for intra-bone comparisons were notably far less varied $(\sigma=0.06 \%$ ). While intra-bone variation is not often investigated, this decidedly small amount of variation within bones is consistent with earlier studies, which found the largest differences in $\delta^{13} \mathrm{C}$ or $\delta^{15} \mathrm{~N}$ between sites of potentially different rates of bone formation (e.g. diaphyseal vs. epiphyseal sites on long bones, 
different portions of mandibles) were on average 0.9\%o or less (Balasse et al., 1997; Sykut et al., 2020; Waters-Rist \& Katzenberg, 2010). Larger intra-bone differences in $\delta^{13} \mathrm{C}$ may occur as a result of switches in diet for which the original and new diet have very different $\delta^{13} \mathrm{C}$ values as is the case for $\mathrm{C}_{3}$ and $\mathrm{C}_{4}$ plants (Gillis et al., 2013). The secondary aim of performing intra-bone comparisons was to determine if the isotopic variation was contingent on whether samples were extracted from sections of cortical bone (the diaphyses) or trabecular bone (the deltoid tuberosities and epiphyseal condyles) in the harp seals. Overall, the difference in $\delta^{13} \mathrm{C}$ and $\delta^{15} \mathrm{~N}$ between cortical and trabecular bone within the same bone appears to be negligible for the bones we tested.

Intra-individual differences in isotopic composition between cortical and trabecular bone are believed to arise due to their respective slower and faster turnover rates reflecting diet during different periods of an individual's life (Clark et al., 2017; Cox $\&$ Sealy, 1997). There have been some counter-arguments that cortical and trabecular bone turn over at similar rates within the same bone (Parfitt, 2002) and that there are only minor differences in collagen turnover among bones (Ubelaker et al., 2006). Harp seals were selected to test for intra-bone variation due to their migratory behaviour, and for the potential to test for changes in diet during different periods of growth in cortical and trabecular bone. Part of their year is spent in the northern and north-eastern Barents Sea where they accumulate blubber stores through intensive feeding (Falk-Petersen et al., 2004). In the early winter, the seals migrate to seek out the drifting pack ice of their breeding grounds; in the case of this data set, the breeding grounds around Newfoundland and Labrador (Bajzak et al., 2011; FalkPetersen et al., 2004). Any variation in diet composition or baseline isotopic variation between regions was not recorded in intra-bone analyses of the subadult seals in this study. There may not have been a sufficient level of isotopic variation between regions to produce significant intra-bone variation. Alternatively, it is possible that because these seals were actively growing, all skeletal elements and both cortical and trabecular bone were remodelling at rapid and comparable rates. Turnover rates in human femoral cortical bone are much more rapid for very young individuals relative to those who have ceased growing (Hedges et al., 2007).

While intra-individual variation was generally low among the different animals analysed, the raccoon showed large amounts of variation in $\delta^{13} \mathrm{C}$, which may be representative of substantial changes in diet. As shown in Fig. 4, the long bones exhibit $\delta^{13} \mathrm{C}$ consistent with a diet of mixed $\mathrm{C}_{3} / \mathrm{C}_{4}$ plant-based foodstuffs, whereas the pelvic and rib bones show a shift in $\delta^{13} \mathrm{C}$ to a more $\mathrm{C}_{4}$ plant-based diet. We suggest that a dietary shift occurred to a more $\mathrm{C}_{4}$-rich diet before the raccoon's death, as bone turnover was likely most rapid in the rib and pelvic bones, which contained a greater amount of trabecular relative to cortical bone. Rib bones are believed to undergo frequent mechanical stress due to respiration, causing remodelling to occur more often (Skedros et al., 2013). In raccoons, it appears that the lower vertebrae and os coxae may also experience greater mechanical strain due to persistent changes to a bipedal posture (especially compared to other quadrupeds; McClearn, 1992), causing these bones to remodel more often than other bones. The arguably slower turnover rate of limb bones may be a result of such bones remodelling less often to avoid loss of strength through the remodelling process (Skedros et al., 2003). 
Fig. 4 Variation in $\delta^{13} \mathrm{C}$ among sampled elements of a southern Ontario raccoon (Procyon lotor). See Online Resource Table S4 for individual bone $\delta^{13} \mathrm{C}$ values

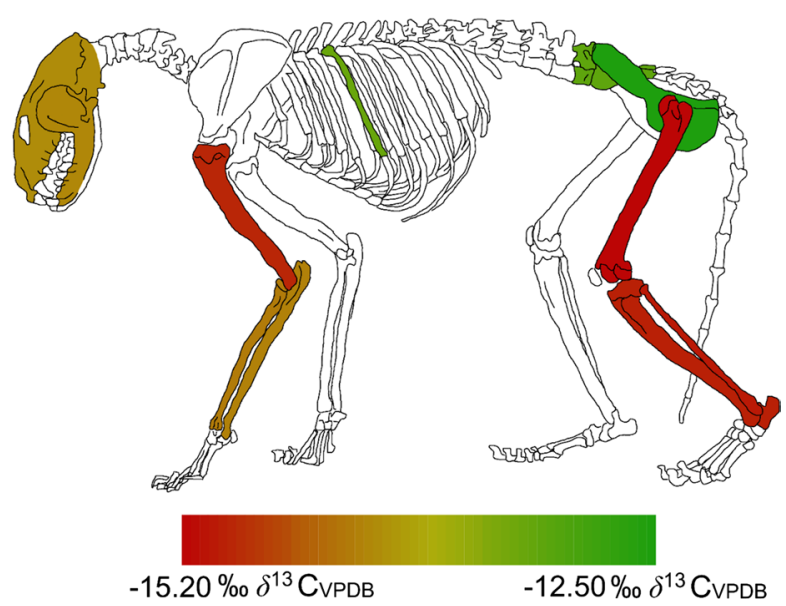

The level of isotopic variation observed in the racoon demonstrates the need for future research into the remodelling of bone and collagen turnover, and how these processes intersect with changes in diet and isotopic composition. As demonstrated by the majority of our dataset, however, large intra-individual variation is uncommon in modern wild and domesticated animals without major dietary changes during their lives. Domesticated animals like pigs, chicken, and turkey are generally provisioned with a homogenised, commercially prepared diet, which results in isotopic consistency over the life of the animal (Marchewka et al., 2013, Manitoba Pork, 2019, Turkey Farmers of Canada, 2019). The diet of beef cattle is controlled but incorporates a predictable shift from graze, in the form of grass and hay, to increased incorporation of grain, until the grain component comprises $90 \%$ of the diet (Cheung et al., 2017). This large shift in diet may be visible as changes in $\delta^{13} \mathrm{C}$ values between bones of differing developmental intervals when domesticated animals are raised mainly on $\mathrm{C}_{3}$ crops (low $\delta^{13} \mathrm{C}$ values) and finished with $\mathrm{C}_{4}$ crops (high $\delta^{13} \mathrm{C}$ values). Wild animals may have less predictable ecologies. For example, fish change diet with growth, shifting trophic position and potentially pivoting to food webs supported by alternate primary production (i.e. littoral/pelagic) giving rise to greater potential for intra-individual variation (Westrheim, 1973). Likewise, the opportunistic, omnivorous diet of raccoons may lead to greater intra-individual variation across skeletal elements with different developmental intervals (Parsons et al., 2013; Schoonover \& Marshall, 1951).

As discussed above, it remains that our proposed $1.50 \%$ value for identifying individuals is subject to very little misclassification. Rare instances in which misclassification may occur would likely include bones with very different turnover rates in individuals with marked shifts between isotopically distinct foods (see also Balasse et al., 1999). If the assemblage was sufficiently large, sampling only from long bone diaphyses could mitigate the small chance of misclassification even further. Finally, based on the variable lipid contamination we observed and its impact on the intra-individual variation, previous studies may have exaggerated the extent 
of intra-individual isotopic variation. Future studies of this nature must prioritise sample pre-treatment protocols that effectively remove lipids.

\section{Conclusion}

A Euclidean distance of $\geq 1.50 \%$ in bivariate $\left(\delta^{13} \mathrm{C}, \delta^{15} \mathrm{~N}\right)$ space provides $95 \%$ confidence that two or more bone fragments originate from distinct individuals. Testing with real and simulated data, the efficacy of this metric (NIDS) was confirmed. It is a conservative and low error means to distinguish individuals within fragmentary archaeological faunal assemblages or those that have a low MNI. Archaeological scientists researching health, diet, environment, and lifeways can apply this metric to their samples to generate larger sample sizes than would be possible if selecting elements based on strict MNI counts. When research involves the application of methods such as stable isotope analysis, ${ }^{14} \mathrm{C}$ dating, or aDNA, it can be particularly important to have confidence in the individuation of the samples as duplication of individuals could alter site chronologies, environmental, dietary, or evolutionary interpretations. Given the low cost of light stable isotope analysis and the comparatively high costs of techniques such as aDNA and ${ }^{14} \mathrm{C}$ dating, this metric is a timesaving, economical method of differentiating individuals.

Supplementary Information The online version contains supplementary material available at https://doi. org/10.1007/s10816-021-09533-7.

Acknowledgements Daniel LaPierre for assistance with R programming. Hymark Dairy Farm, Katherine Patterson, and Eric Guiry for the donation of animal carcasses and bones for analysis. Dr. Eugene Morin for the use of the Trent University Archaeology Wet lab for carcass processing. Joy for additional bone processing of the dog chews and encouragement throughout the project. This is Trent Environmental Archaeology Lab Graduate Research on Isotopic Methodologies project \#1.

Author Contribution Corrie Hyland: data curation; formal analysis; investigation; visualisation; writing — original draft; writing — review and editing. Michael B. Scott: formal analysis; investigation; writing — original draft; writing — review and editing. Jennifer Routledge: formal analysis; investigation; writing — original draft; writing — review and editing. Dr. Paul Szpak: conceptualisation; formal analysis; funding acquisition; methodology; project administration; resources; supervision; writing — review and editing.

Funding This study was financially supported by the Canada Research Chairs Program (PS, 950231012), the Ontario Graduate Scholarship, the Social Sciences and Humanities Research Council, and the Bagnani Trust.

Availability of Data and Material All original data is available in the associated online resources files and tables.

Code Availability Not applicable.

\section{Declarations}

Ethics Approval Not applicable. 
Consent to Participate Not applicable.

Consent for Publication Not applicable.

Conflict of Interest The authors declare no competing interests.

Open Access This article is licensed under a Creative Commons Attribution 4.0 International License, which permits use, sharing, adaptation, distribution and reproduction in any medium or format, as long as you give appropriate credit to the original author(s) and the source, provide a link to the Creative Commons licence, and indicate if changes were made. The images or other third party material in this article are included in the article's Creative Commons licence, unless indicated otherwise in a credit line to the material. If material is not included in the article's Creative Commons licence and your intended use is not permitted by statutory regulation or exceeds the permitted use, you will need to obtain permission directly from the copyright holder. To view a copy of this licence, visit http://creativecommons.org/licen ses/by/4.0/.

\section{References}

Ambrose, S. H. (1990). Preparation and characterization of bone and tooth collagen for isotopic analysis. Journal of Archaeological Science, 17(4), 431-451. https://doi.org/10.1016/0305-4403(90)90007-R

Bajzak, C. E., Hammill, M. O., Stenson, G. B., \& Prinsenberg, S. (2011). Drifting away: Implications of changes in ice conditions for a pack-ice-breeding phocid, the harp seal (Pagophilus groenlandicus). Canadian Journal of Zoology, 89(11), 1050-1062. https://doi.org/10.1139/z11-081

Balasse, M., Bocherens, H., \& Mariotti, A. (1999). Intra-bone variability of collagen and apatite isotopic composition used as evidence of a change of diet. Journal of Archaeological Science, 26(6), 593598. https://doi.org/10.1006/jasc.1998.0376

Balasse, M., Bocherens, H., Tresset, A., Mariotti, A., \& Vigne, J. D. (1997). Emergence de la production laitière au Néolithique? Contribution de l'analyse isotopique d'ossements de bovins archéologiques. Comptes Rendus De L'académie Des Sciences-Series IIA-Earth and Planetary Science, 325(12), 1005-1010. https://doi.org/10.1016/S1251-8050(97)82382-8

Cheung, C., Jing, Z., Tang, J., Weston, D. A., \& Richards, M. P. (2017). Diets, social roles, and geographical origins of sacrificial victims at the royal cemetery at Yinxu, Shang China: New evidence from stable carbon, nitrogen, and sulfur isotope analysis. Journal of Anthropological Archaeology, 48, 28-45. https://doi.org/10.1016/j.jaa.2017.05.006

Clark, C. T., Horstmann, L., \& Misarti, N. (2017). Quantifying variability in stable carbon and nitrogen isotope ratios within the skeletons of marine mammals of the suborder Caniformia. Journal of Archaeological Science: Reports, 15, 393-400. https://doi.org/10.1016/j.jasrep.2017.09.007

Cox, G., \& Sealy, J. (1997). Investigating identity and life histories: Isotopic analysis and historical documentation of slave skeletons found on the Cape Town foreshore, South Africa. International Journal of Historical Archaeology, 1(3), 207-224. https://doi.org/10.1023/A:1027349115474

Canadian Cattlement's Association and Beef Information Centre (2010). What do beef cattle eat? http:// www.ontariobeef.com/uploads/userfiles/files/what $\% 20$ do\%20beef\%20cattle\%20eat.pdf Accessed May 28, 2019.

Corbett, D.G., Causey, D., Clementz, M., Koch, P.L., Doroff, A., Lefevre, C., \& West, D. (2008). Aleut hunters, sea otters, and sea cows: Three thousand years of interactions in the western Aleutian Islands, Alaska. Human Impacts on Ancient Marine Ecosystems: A Global Perspective. Torben C. Rick and Jon M. Erlandson, eds, 43-75 https://doi.org/10.1525/9780520934290-005

DeNiro, M. J. (1985). Postmortem preservation and alteration of in vivo bone collagen isotope ratios in relation to palaeodietary reconstruction. Nature, 317, 806-809. https://doi.org/10.1038/317806a0

Elliott, Alan C., \& Woodward, W.A. (2007). Statistical analysis quick reference guidebook: With SPSS examples. SAGE. 
Fahy, G. E., Deter, C., Pitfield, R., Miszkiewicz, J. J., \& Mahoney, P. (2017). Bone deep: Variation in stable isotope ratios and histomorphometric measurements of bone remodelling within adult humans. Journal of Archaeological Science, 87, 10-16. https://doi.org/10.1016/j.jas.2017.09.009

Falk-Petersen, S., Haug, T., Nilssen, K. T., Wold, A., \& Dahl, T. M. (2004). Lipids and trophic linkages in harp seal (Phoca groenlandica) from the eastern Barents Sea. Polar Research, 23(1), 43-50. https:// doi.org/10.1111/j.1751-8369.2004.tb00128.x

Folch, J., Lees, M., \& Stanley, G. H. S. (1957). A simple method for the isolation and purification of total lipids from animal tissues. Journal of Biological Chemistry, 226, 497-509.

Geyh, M. A. (2001). Bomb radiocarbon dating of animal tissues and hair. Radiocarbon, 43(2B), 723730. https://doi.org/10.1017/S0033822200041382

Gillis, R., Bréhard, S., Bălăşescu, A., Ughetto-Monfrin, J., Popovici, D., Vigne, J. D., \& Balasse, M. (2013). Sophisticated cattle dairy husbandry at Borduşani-Popină (Romania, fifth millennium BC): The evidence from complementary analysis of mortality profiles and stable isotopes. World Archaeology, 45(3), 447-472. https://doi.org/10.1080/00438243.2013.820652

Gorlova, E. N., Krylovich, O. A., Tiunov, A. V., Khasanov, B. F., Vasyukov, D. D., \& Savinetsky, A. B. (2015). Stable-isotope analysis as a method of taxonomical identification of archaeozoological material. Archaeology, Ethnology and Anthropology of Eurasia, 43(1), 110-121. https://doi.org/10.1016/j.aeae. 2015.07.013

Guiry, E. J., \& Szpak, P. (2020). Quality control for modern bone collagen stable carbon and nitrogen isotope measurements. Methods in Ecology and Evolution, 11, 1049-1060. https://doi.org/10.1111/2041-210X. 13433

Hedges, R. E., Clement, J. G., Thomas, C. D. L., \& O’Connell, T. C. (2007). Collagen turnover in the adult femoral mid-shaft: Modeled from anthropogenic radiocarbon tracer measurements. American Journal of Physical Anthropology, 133(2), 808-816. https://doi.org/10.1002/ajpa.20598

Hobson, K. A., \& Clark, R. G. (1992). Assessing avian diets using stable isotopes I: Turnover of 13C in tissues. The Condor, 94(1), 181-188. https://doi.org/10.2307/1368807

Hobson, K. A., \& Schwarcz, H. (1986). The variation in $\delta^{13} \mathrm{C}$ values in bone collagen for two wild herbivore populations: Implications for palaeodiet studies. Journal of Archaeological Science, 13, 101-106. https://doi.org/10.1016/0305-4403(86)90001-4

Jørkov, M. L. S., Heinemeier, J., \& Lynnerup, N. (2009). The petrous bone-A new sampling site for identifying early dietary patterns in stable isotopic studies. American Journal of Physical Anthropology, 138(2), 199-209. https://doi.org/10.1002/ajpa.20919

Manolagas, S. C. (2000). Birth and death of bone cells: Basic regulatory mechanisms and implications for the pathogenesis and treatment of osteoporosis. Endocrine Reviews, 21(2), 115-137. https://doi.org/10. 1210/edrv.21.2.0395

Marchewka, J., Watanabe, T. T. N., Ferrante, V., \& Estevez, I. (2013). Review of the social and environmental factors affecting the behavior and welfare of turkeys (Meleagris gallopavo). Poultry Science, 92(6), 1467-1473. https://doi.org/10.3382/ps.2012-02943

Matsubayashi, J., \& Tayasu, I. (2019). Collagen turnover and isotopic records in cortical bone. Journal of Archaeological Science, 106, 37-44. https://doi.org/10.1016/j.jas.2019.03.010

McClearn, D. (1992). Locomotion, posture, and feeding behavior of kinkajous, coatis, and raccoons. Journal of Mammalogy, 73, 245-261. https://doi.org/10.2307/1382055

Marshall, F., \& Pilgram, T. (1993) NISP vs. MNI in Quantification of Body-Part Representation. American Antiquity 58(2): 261-69. https://doi.org/10.2307/281968.

Manitoba Pork (2019). What do pigs eat? https://www.manitobapork.com/on-the-farm/how-pigs-are-raised/ what-do-pigs-eat Accessed May 29, 2019.

Olsen, K. C., White, C. D., Longstaffe, F. J., von Heyking, K., McGlynn, G., Grupe, G., \& Rühli, F. J. (2014). Intraskeletal isotopic compositions $\left(\delta^{13} \mathrm{C}, \delta^{15} \mathrm{~N}\right)$ of bone collagen: Nonpathological and pathological variation. American Journal of Physical Anthropology, 153(4), 598-604. https://doi.org/10.1002/ajpa. 22459

Parfitt, A. M. (2002). Misconceptions (2): Turnover is always higher in cancellous than in cortical bone. Bone, 30(6), 807-809.

Parsons, A. W., Simons, T. R., O’Connell, A. F., \& Stoskopf, M. K. (2013). Demographics, diet, movements, and survival of an isolated, unmanaged raccoon Procyon lotor (Procyonidae, Carnivora) population on the Outer Banks of North Carolina. Mammalia, 77(1), 21-30. https://doi.org/10.1515/mamma lia-2011-0138

Pollard, A. M., Ditchfield, P., Piva, E., Wallis, S., Falys, C., \& Ford, S. (2012). 'Sprouting like cockle amongst the wheat': The St Brice's Day massacre and the isotopic analysis of human bones from St 
John's College, Oxford. Oxford Journal of Archaeology, 31(1), 83-102. https://doi.org/10.1111/j.14680092.2011.00380.x

R Core Team. (2013). R: A language and environment for statistical computing. R Foundation for Statistical Computing, Vienna, Austria. URL http://www.R-project.org/.

Riofrío-Lazo, M., \& Aurioles-Gamboa, D. (2013). Timing of isotopic integration in marine mammal skull: Comparative study between calcified tissues. Rapid Communications in Mass Spectrometry, 27(9), 1076-1082. https://doi.org/10.1002/rcm.6556

Schoonover, L. J., \& Marshall, W. H. (1951). Food habits of the raccoon (Procyon lotor hirtus) in northcentral Minnesota. Journal of Mammalogy, 32(4), 422-428. https://doi.org/10.2307/1375790

Schoeninger, M. J., De Niro, M. J., Tauber, H. (1983). Stable nitrogen isotope ratios of bone collagen reflect marine and terrestrial components of prehistoric human diet. Science, 220, 1381-1383. https://doi.org/ 10.1126/science.6344217

Sealy, J., Armstrong, R., \& Schrire, C. (1995). Beyond lifetime averages: Tracing life histories through isotopic analysis of different calcified tissues from archaeological human skeletons. Antiquity, 69(263), 290-300. https://doi.org/10.1017/S0003598X00064693

Skedros, J. G., Knight, A. N., Clark, G. C., Crowder, C. M., Dominguez, V. M., Qiu, S., Mulhern, D. M., Donahue, S. W., Busse, B., Hulsey, B. I., Zedda, M., \& Sorenson, S. M. (2013). Scaling of Haversian canal surface area to secondary osteon bone volume in ribs and limb bones. American Journal of Physical Anthropology, 151, 230-244. https://doi.org/10.1002/ajpa.22270

Skedros, J. G., Sybrowsky, C. L., Parry, T. R., \& Bloebaum, R. D. (2003). Regional differences in cortical bone organization and microdamage prevalence in Rocky Mountain mule deer. The Anatomical Record Part a: Discoveries in Molecular, Cellular, and Evolutionary Biology, 274A, 837-850. https://doi.org/ 10.1002/ar.a.10102

Snyder, W. S., Cook, M. J., Nasset, E. S., Karhausen, L. R., Howells, G. P., \& Tipton, I. H. (1975). Report of the task group on reference man. Pergamon Press.

Sykut, M., Pawełczyk, S., Borowik, T., Pokorny, B., Flajšman, K., \& Niedziałkowska, M. (2020). Intraindividual and interpopulation variability in carbon and nitrogen stable isotope ratios of bone collagen in the modern red deer (Cervus elaphus). Journal of Archaeological Science: Reports, 34, 102669.

Szpak, P., \& Buckley, M. (2020). Sulfur isotopes $\left(\delta^{34} S\right)$ in Arctic marine mammals: Indicators of benthic vs. pelagic foraging. Marine Ecology Progress Series, 653, 205-216. https://doi.org/10.3354/meps13493

Szpak, P., Julien, M.-H., Royle, T. C. A., Savelle, J. M., Yang, D. Y., \& Richards, M. P. (2020). Sexual differences in the foraging ecology of 19th century beluga whales (Delphinapterus leucas) from the Canadian High Arctic. Marine Mammal Science, 36, 451-471. https://doi.org/10.1111/mms.12655

Szpak, P., Millaire, J.-F., White, C. D., Bourget, S., \& Longstaffe, F. J. (2016). Life histories of sacrificed camelids from Huancaco (Virú Valley). In H. D. Klaus \& J. M. Toyne (Eds.), Reconstructing sacrifice on the north coast of Peru: Archaeological studies of ritual violence in the ancient Andes (pp. 319341). University of Texas Press.

Szpak, P., Millaire, J.-F., White, C. D., Lau, G. F., Surette, F., \& Longstaffe, F. J. (2015). Origins of prehispanic camelid wool textiles from the north and central coasts of Peru traced by carbon and nitrogen isotopic analyses. Current Anthropology, 56, 449-459. https://doi.org/10.1086/680873

Szpak, P., Millaire, J.-F., White, C. D., \& Longstaffe, F. J. (2014). Small scale camelid husbandry on the north coast of Peru (Virú Valley): Insight from stable isotope analysis. Journal of Anthropological Archaeology, 36, 110-129. https://doi.org/10.1016/j.jaa.2014.08.005

Szpak, P., Savelle, J. M., Conolly, J., \& Richards, M. P. (2019). Variation in late Holocene marine environments in the Canadian Arctic Archipelago: Evidence from ringed seal bone collagen stable isotope compositions. Quaternary Science Reviews, 211, 136-155. https://doi.org/10.1016/j.quascirev.2019.03. 016

Szpak, P., \& Valenzuela, D. (2020). Camelid husbandry in the Atacama Desert? A stable isotope study of camelid bone collagen and textiles from the Lluta and Camarones Valleys, northern Chile. PLoS ONE, 15, e0228332. https://doi.org/10.1371/journal.pone.0228332

Szpak, P (2013). Stable isotope ecology and human-animal interactions in northern Peru. Ph.D. Dissertation. Western University, London, Ontario. $381 \mathrm{pp}$.

Stenhouse M.J., \& Baxter M.S. (1979). The uptake of bomb 14C in humans. Radiocarbon Dating. R. Berger and H.E. Suess, eds, 324-341.

Turkey Farmers of Canada (2019). What turkeys eat. https://www.turkeyfarmersofcanada.ca/on-the-farm/ what-turkeys-eat-3/ Accessed May 26, 2019. 
Ubelaker, D. H., Buchholz, B. A., \& Stewart, J. E. (2006). Analysis of artificial radiocarbon in different skeletal and dental tissue types to evaluate date of death. Journal of Forensic Sciences, 51(3), 484-488. https://doi.org/10.1111/j.1556-4029.2006.00125.x

Waters-Rist, A. L., \& Katzenberg, M. A. (2010). The effect of growth on stable nitrogen isotope ratios in subadult bone collagen. International Journal of Osteoarchaeology, 20(2), 172-191. https://doi.org/10. 1002/oa. 1017

Webb, E. C., Stewart, A., Miller, B., Tarlton, J., \& Evershed, R. P. (2016). Age effects and the influence of varying proportions of terrestrial and marine dietary protein on the stable nitrogen-isotope compositions of pig bone collagen and soft tissues from a controlled feeding experiment. STAR: Science \& Technology of Archaeological Research, 2(1), 54-66. https://doi.org/10.1080/20548923.2015.1133121

Westrheim, S. J. (1973). Age determination and growth of Pacific ocean perch (Sebastes alutus) in the northeast Pacific Ocean. Journal of the Fisheries Board of Canada, 30(2), 235-247. https://doi.org/10.1139/ f73-041

Publisher's note Springer Nature remains neutral with regard to jurisdictional claims in published maps and institutional affiliations. 